\title{
MOLECULAR BEAM EPITAXY OF HIGH QUALITY InGaN ALLOYS USING AMMONIA: OPTICAL AND STRUCTURAL PROPERTIES.
}

\author{
Nicolas Grandjean*, Jean Massies*, Mathieu Leroux*, Marguerite Laügt*, Philippe \\ Vennéguès*, Stéphane Dalmasso*, Pierre Ruterana**, Lionel Hirsch***, Serge Barrière*** \\ * CRHEA-CNRS, Rue Bernard Grégory, Sophia Antipolis, 06560 Valbonne, France \\ ** LERMAT-CNRS, 6 Bd Maréchal Juin, 14050 Caen Cedex, France \\ *** IXL, ENSERB-CNRS, 351 cours de la libération, 33405 Talence, France
}

Cite this article as: MRS Internet J. Nitride Semicond. Res. 4S1.G3.59 (1999)

\begin{abstract}
The growth of InGaN layers was carried out by molecular beam epitaxy (MBE). The nitrogen precursor was ammonia. The optical and structural properties of the InGaN layers have been investigated by transmission electron microscopy (TEM), x-ray diffraction (XRD) and photoluminescence (PL). For optimized growth conditions, the PL spectrum of InGaN ( $\mathrm{x}=0.1$ ) alloy is narrow (FWHM $\leq 50 \mathrm{meV}$ ) and the Stokes shift measured by PL excitation is weak ( $<50 \mathrm{meV}$ ), i.e. near band edge transitions are observed. Under these conditions, flat surfaces can be obtained, and InGaN/GaN quantum wells (QWs) with sharp interfaces can be grown. On the other hand, when growth conditions depart from a narrow optimum window, the structural quality of the samples strongly degrade, whereas the luminescence spectra are dominated by deep levels, exhibiting a strong Stokes shift. MBE grown light emitting diodes (LEDs) using InGaN/GaN QWs have been fabricated. Their electroluminescence (EL) peaks at $440 \mathrm{~nm}$ at $300 \mathrm{~K}$.
\end{abstract}

\section{INTRODUCTION}

The ternary alloy InGaN has a direct band gap ranging from $1.9 \mathrm{eV}(\mathrm{InN})$ to $3.4 \mathrm{eV}(\mathrm{GaN})$ and has now shown its potentiality for light emitters in the visible range of the electromagnetic spectrum. [1]. Most of the nitride based structures and devices are currently fabricated using metal-organic chemical vapor deposition (MOCVD), which has proven its ability for the growth of high quality nitrides [1]. MBE is however emerging as an alternative growth technique. It allows the use of high efficiency in situ characterization tools (reflection high energy electron diffraction (RHEED), mass spectroscopy...) and high quality GaN can be grown in the two versions of the $\mathrm{MBE}$ of nitrides, i.e. using $\mathrm{NH}_{3}$ or an $\mathrm{N}_{2}$ plasma source [2,3]. Presently, apart MOCVD, InGaN/GaN QW based LEDs have been reported only by plasmaassisted MBE growth [4]. We show in this paper that $\mathrm{NH}_{3}$ is also well suited for achieving InGaN/GaN QWs with sharp interfaces. LEDs have been processed from that material and exhibit room temperature EL at $440 \mathrm{~nm}$.

\section{EXPERIMENTS}

The growth of GaN and InGaN was carried out in a Riber $32 \mathrm{P}$ MBE system equipped with RHEED and laser reflectivity facilities. Ga and In were provided by double-filament effusion cells. A flow of $50 \mathrm{sccm}$ of purified $\mathrm{NH}_{3}$ was used for the growth of both $\mathrm{GaN}$ and InGaN. 
Before growing the InGaN alloys or QW structures, $2 \mu \mathrm{m}$-thick GaN epilayer were deposited on (0001) sapphire substrates following the procedure described in ref. [3]. The substrate temperature was decreased around $600^{\circ} \mathrm{C}$ to grow InGaN. The growth rate is $0.2 \mu \mathrm{m} / \mathrm{h}$ and the thicknesses ranging from 70 to $200 \mathrm{~nm}$. Concerning the In composition, it has been checked by XRD, Rutherford back scattering, and RHEED intensity oscillations. The two first techniques give roughly the same In composition while RHEED leads to larger values. Actually, RHEED intensity oscillations are observed only at the beginning of the growth. Therefore, a growth transient which can be provoked in particular by In surface segregation could affect the measurements. The structural properties of the layers were assessed by TEM and XRD. The optical properties were studied by PL using a $10 \mathrm{~mW} \mathrm{HeCd}$ laser as excitation source.

\section{RESULTS AND DISCUSSIONS}

The specificity of InGaN MBE growth with $\mathrm{NH}_{3}$, compared to plasma sources, is the cracking of this nitrogen precursor on the growing surface which depends on the substrate temperature. This implies that the amount of nitrogen active species is a function of the substrate temperature. For instance, it has been reported that the decomposition of $\mathrm{NH}_{3}$ below $450^{\circ} \mathrm{C}$ is insignificant [5]. When increasing the substrate temperature, the $\mathrm{NH}_{3}$ efficiency increases too but remains rather low $\left(4 \%\right.$ at $\left.700^{\circ} \mathrm{C}\right)$. Therefore, with the aim of growing GaInN alloy, we have to take care of the high dissociation rate of $\mathrm{InN}$, the high In volatility and the $\mathrm{NH}_{3}$ cracking efficiency pattern. We have determined that the best InGaN properties are obtained for temperatures ranging between 570 and $620^{\circ} \mathrm{C}$.

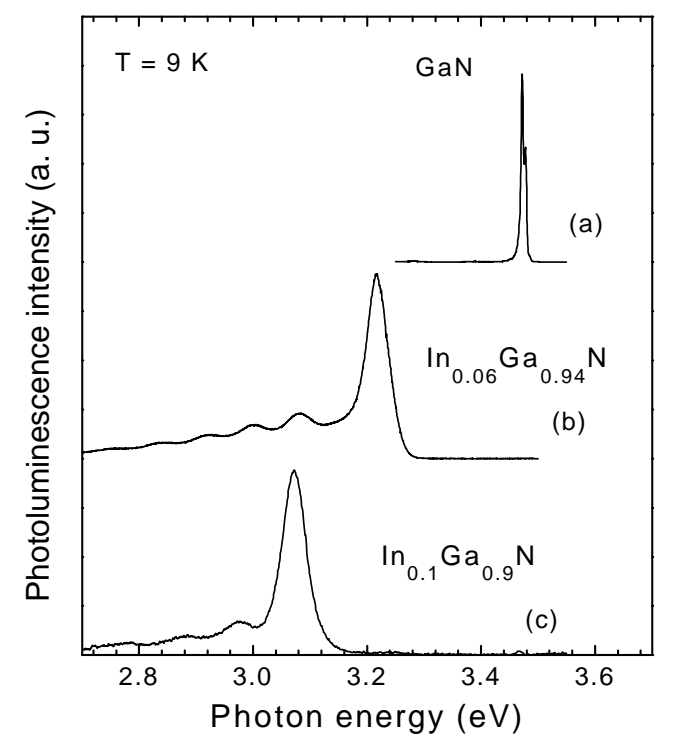

Figure 1: $9 \mathrm{~K}$ PL spectra of InGaN layers

Fig. 1 displays two low temperature $(9 \mathrm{~K}) \mathrm{PL}$ spectra of $\mathrm{InGaN}$ layers grown at $\sim 600^{\circ} \mathrm{C}$ with a growth rate of $0.2 \mu \mathrm{m} / \mathrm{h}$ (the $\mathrm{GaN}$ spectrum is given in Fig. 1(a) as reference). The indium compositions are $6 \%$ and $10 \%$ in Figs. 1(b) and 1(c), respectively. A sharp PL peak (full width at half maximum (FWHM) of $\sim 50 \mathrm{meV}$ ) is observed for the two In compositions. The transition energies are $3.22 \mathrm{eV}$ and $3.07 \mathrm{eV}$. The PL spectra of InGaN layers exhibits also 
deep luminescence on the low energy side of the main PL peak. Unfortunately, interference makes difficult to ascribe this luminescence to standard shallow donor acceptor pair recombinations or to deep-levels, or other origins (In rich and/or strain relaxed areas). When growth conditions depart from an optimum window, this deep-level PL dominates the spectra. Fig. 2 shows a cross section TEM image of a thin $\mathrm{In}_{0.06} \mathrm{Ga}_{0.94} \mathrm{~N}$ layer $(160 \mathrm{~nm})$ deposited at $570^{\circ} \mathrm{C}$ and $0.18 \mu \mathrm{m} / \mathrm{h}$ on $\mathrm{GaN}$ template. One can see that no further defects are introduced in the InGaN layer. Only the preexistent dislocations propagate into the InGaN layer resulting in pits at the surface as for the case of MOCVD growth [6].

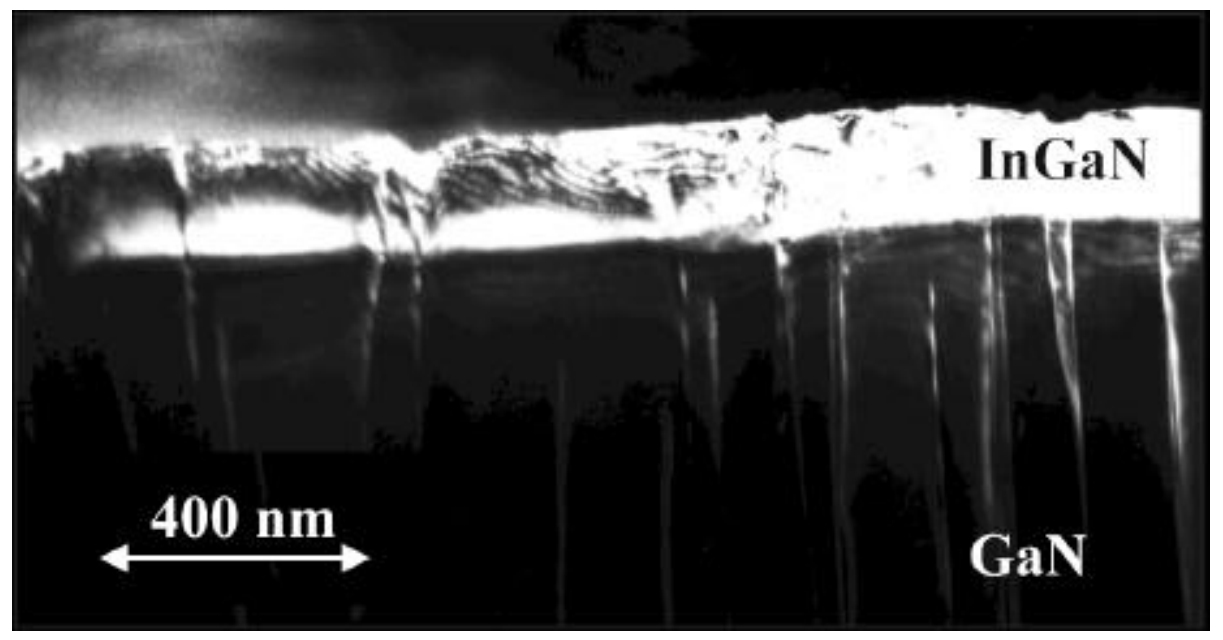

Figure 2: TEM image in cross section of an $\operatorname{In}_{0.6} \mathrm{Ga}_{0.94} \mathrm{~N}$ layer grown at $570^{\circ} \mathrm{C}$ and $0.18 \mu \mathrm{m} / \mathrm{h}$

The strain state of the $\mathrm{In}_{0.06} \mathrm{Ga}_{0.94} \mathrm{~N}$ layer has been checked by XRD reciprocal space mapping of the [-105] and [105] reflections. Fig. 3 shows that the 160nm-thick InGaN layer is almost perfectly pseudomorphically strained onto the GaN template.

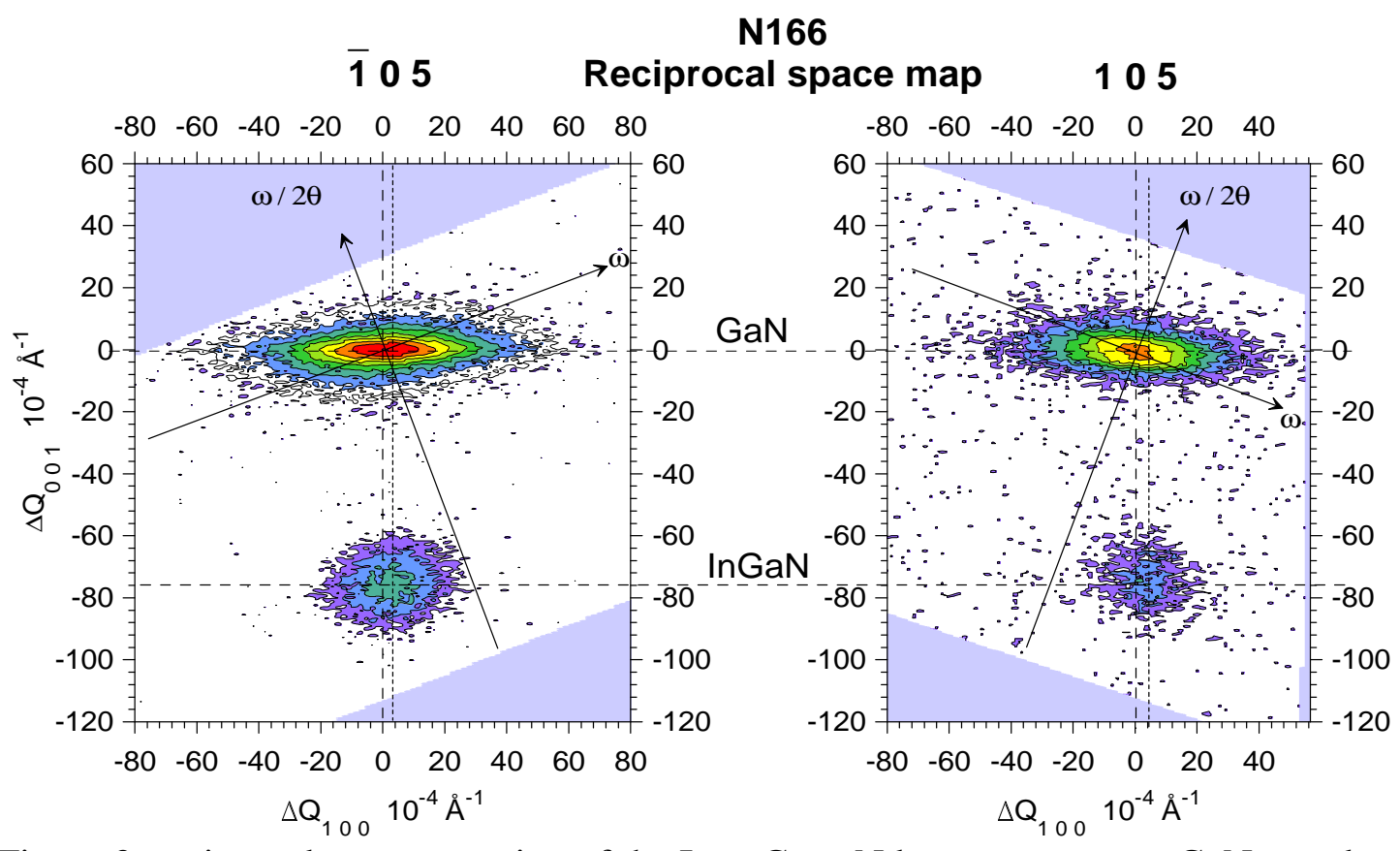

Figure 3: reciprocal space mapping of the $\operatorname{In}_{0.06} \mathrm{Ga}_{0.94} \mathrm{~N}$ layer grown on a $\mathrm{GaN}$ template 


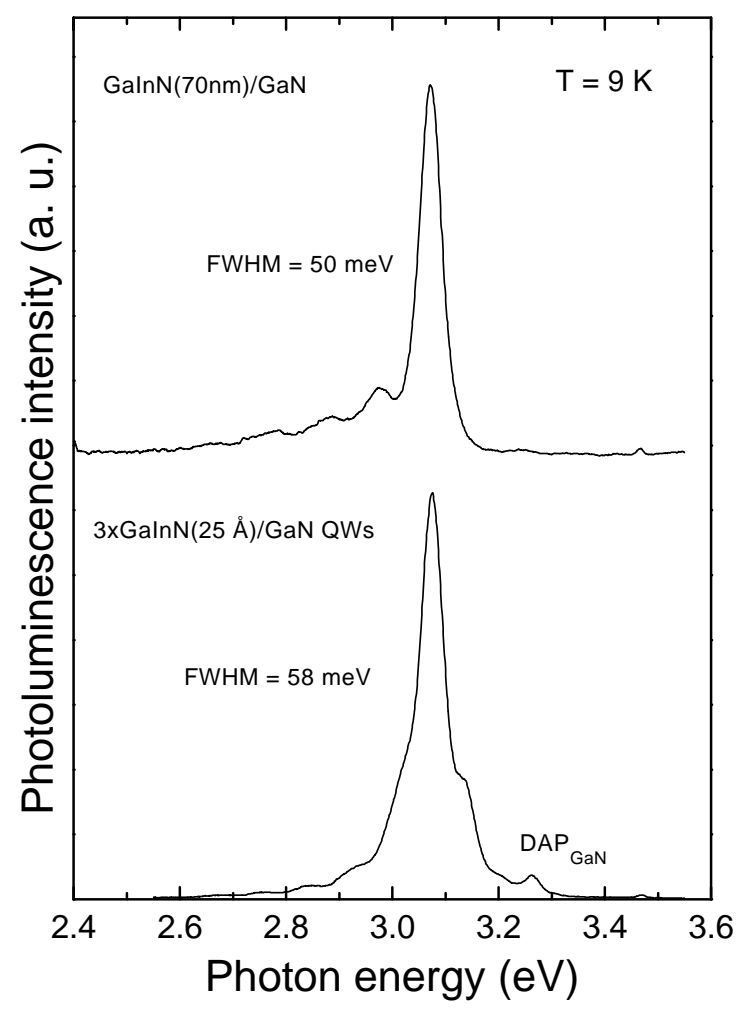

Figure 4: 9 K PL spectra of a GaInN layer (70nm) and of a 3xInGaN(25 $) / G a N(35 \AA)$ QWs

The InGaN alloys, previously characterized, have been used to grow InGaN/GaN QWs. Fig. 4 displays the $9 \mathrm{~K}$ PL spectrum of $3 \mathrm{GaInN} / \mathrm{GaN}$ QWs of width $25 \AA$. The In composition is about $10 \%$. For comparison, the upper spectrum in Fig. 4 corresponds to a bulk GaInN of similar composition. The peak energy of the QW sample is only slightly blue shifted (3.08 $\mathrm{eV})$ relative to that of the bulk $(3.07 \mathrm{eV})$. Actually, it is known that the energy of nitride QWs is determined by the interplay between quantum confinement and polarization field [7,8].

LEDs with a $5 \operatorname{InGaN}(25 \AA) / \mathrm{GaN}(35 \AA)$ active region have been grown on sapphire by MBE and characterized by TEM. Fig. 5 and 6 show low magnification and high resolution TEM image of the structure, respectively. One can clearly distinguish the wells. It should be remarked that the first well is thinner that the other ones (Fig. 7). The In surface segregation effect is likely responsible for such a feature.

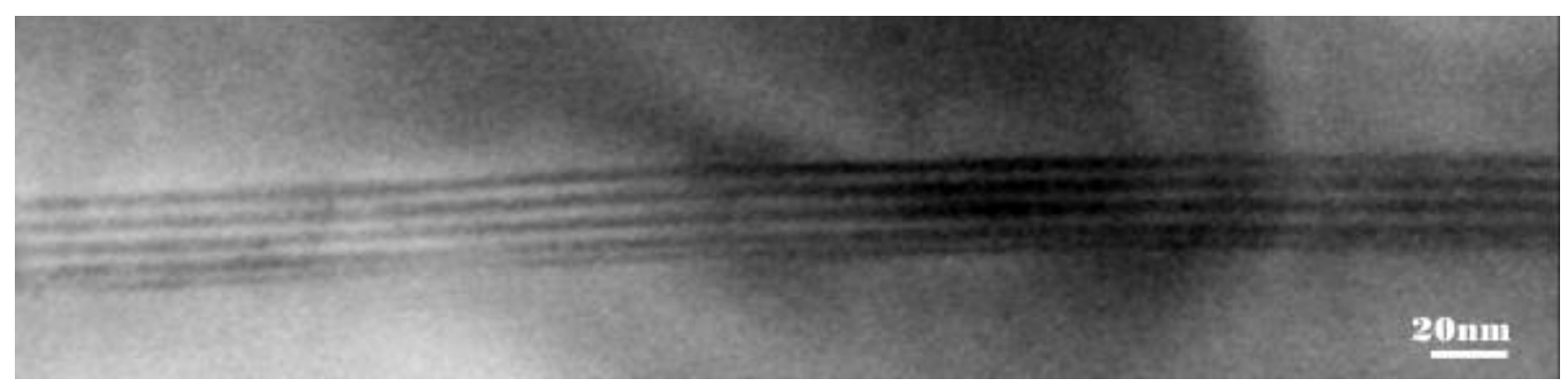

Figure 5: dark field TEM image of the $5 \mathrm{GaInN}(25 \AA) / \mathrm{GaN}(35 \AA)$ QWs (LED active region) 


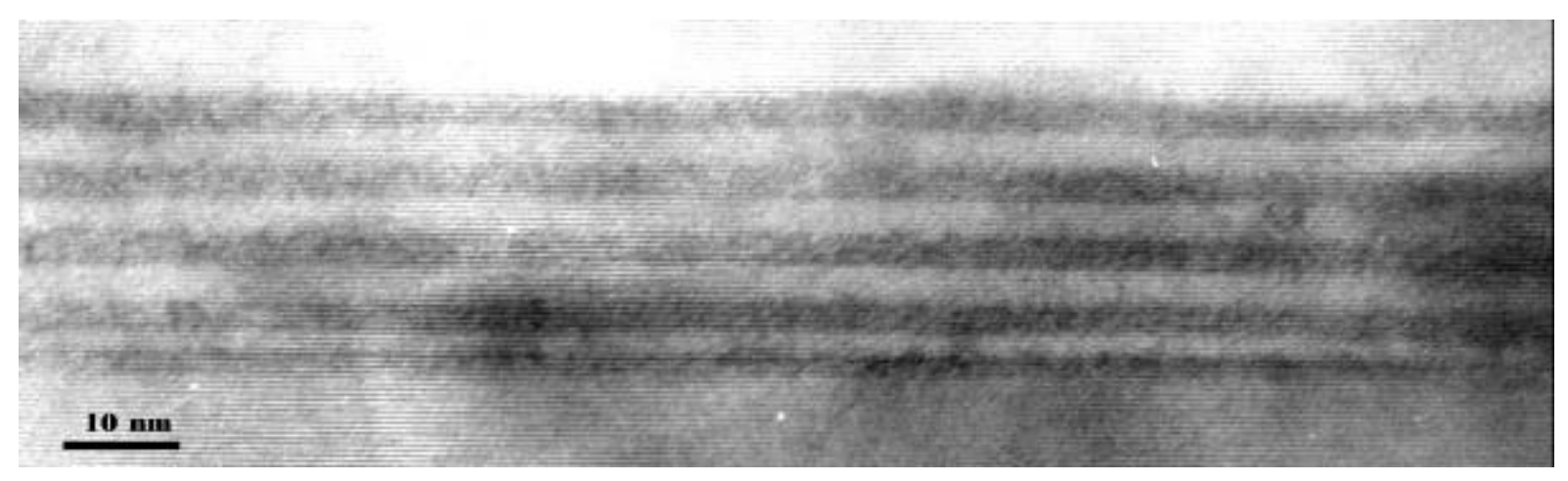

Figure 6: high resolution TEM image of LED active region

The room temperature electroluminescence spectrum of the LED of Figs. 5 and 6 is reported in Fig. 7. The EL emission is in the blue region of the visible electromagnetic spectrum with EL maxima at $440 \mathrm{~nm}$ for injection currents of $20 \mathrm{~mA}$. The linewidth of the EL spectrum is $40 \mathrm{~nm}$. A maximum output power of $10 \mu \mathrm{W}$ at $20 \mathrm{~mA}$ has been measured using a calibrated Si diode. This is still low compared to the current MOCVD state of the art. Nevertheless, the demonstration of LEDs based on InGaN/GaN MQW structures grown entirely by MBE is encouraging in view of the fabrication of more sophisticated devices. Actually, epitaxial lateral overgrowth (ELOG) substrates will certainly boost the MBE based nitride device development in the near future.

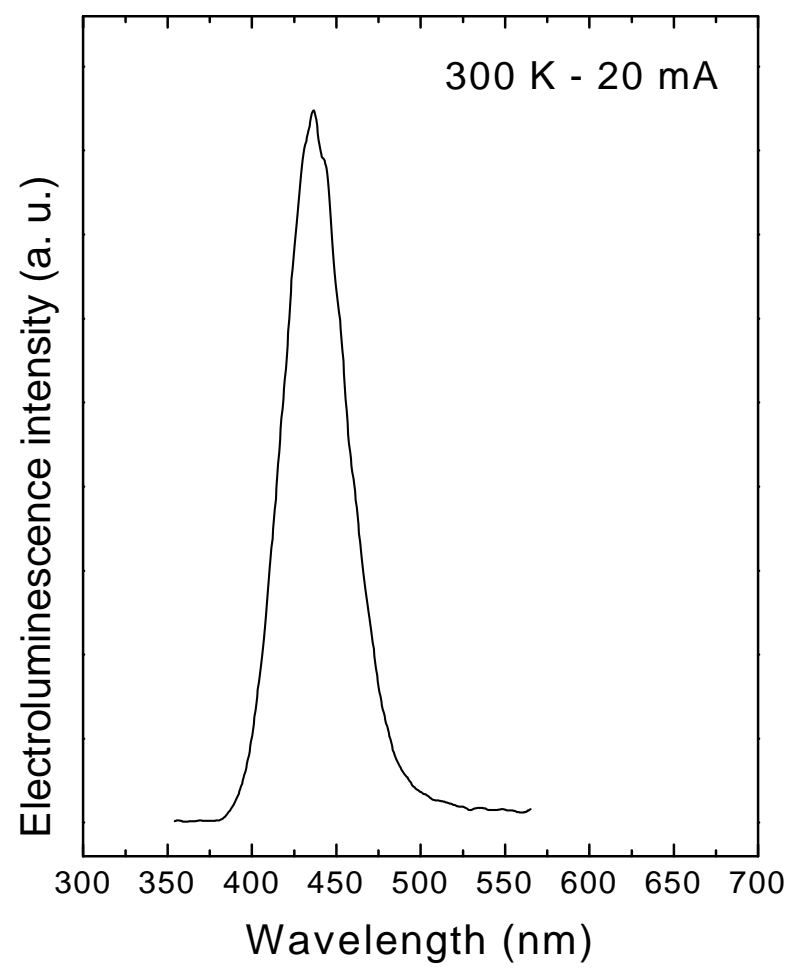

Figure 7: room temperature EL of a LED with a $5 \mathrm{GaInN}(25 \AA) / \mathrm{GaN}(35 \AA) \mathrm{QW}$ active region

\section{CONCLUSIONS}


InGaN layers have been grown by MBE using ammonia as nitrogen precursor. The PL spectrum of $\operatorname{InGaN}(\mathrm{x} \leq 0.1)$ alloy is narrow $(\mathrm{FWHM} \leq 50 \mathrm{meV})$ and TEM reveals InGaN layers of reasonable quality. They are pseudomorphically strained on the GaN template as demonstrated by XRD reciprocal space mapping. InGaN/GaN quantum wells with sharp interfaces have been grown and inserted in the active region of LEDs. Their room temperature electroluminescence yields blue emission at $440 \mathrm{~nm}$ with a FWHM of $40 \mathrm{~nm}$.

\section{ACKNOWLEDGMENTS}

This work is supported in part by BRITE EURAM EC contract $\mathrm{N}^{\circ}$ BRPR-CT96-0334 "ANISET".

\section{REFERENCES}

[1] S. Nakamura and G. Fasol, The Blue Laser Diode, (Springer, Berlin (1997))

[2] G.Popovici, H.Morkoç and S.Mohammad, in Group III Nitride Semiconductor

Compounds, edited by B.Gil (Clarendon Press, Oxford (1998)) and references therein.

[3] N. Grandjean, J. Massies, P. Vennéguès, M. Leroux, F. Demangeot, M. Renucci, and J. Frandon, J. Appl. Phys. 83, 1379 (1998)

[4] H. Tews, R. Averbeck, A. Graber and H. Riechert: Electron. Lett. 32, 2004 (1996)

[5] M. Mesrine, N. Grandjean and J. Massies: Appl. Phys. Lett. 72, 350 (1998)

[6] Y. Kawaguchi, M. Shimizu, M. Yamaguchi, K. Hiramatsu, N. Sawaki, W. Taki, H. Tsuda, N. Kuwano, K. Oki, T. Zheleva, R.F. Davis, J. Cryst. Growth 189/190, 24 (1998)

[7] T.Takeuchi, S.Sota, H.Sakai, H.Amanoa, I.Akasaki, Y.Kaneko, S.Nakagawa, Y.Yamaoka, N.Yamada, J. Cryst. Growth. 189/190, 616 (1998)

[8] S.F. Chichibu, A.C. Abare, M.S. Minsky, S. Keller, S.B. Leisher, J.E. Bowers, E. Hu, U.K. Mishra, L.A. Coldren, S.P. DenBaars, and T. Sota, Appl. Phys. Lett. 73, 2006 (1998) 